\title{
PET Molecular Targets and Near-Infrared Fluorescence Imaging of Atherosclerosis
}

\author{
Csilla Celeng $^{1} \cdot$ Bart de Keizer $^{1} \cdot$ Béla Merkely $^{2} \cdot$ Pim de Jong $^{1} \cdot$ Tim Leiner $^{1} \cdot$ Richard A. P. Takx $^{1}$
}

Published online: 12 February 2018

(C) The Author(s) 2018. This article is an open access publication

\begin{abstract}
Purpose of Review With this review, we aim to summarize the role of positron emission tomography (PET) and near-infrared fluorescence imaging (NIRF) in the detection of atherosclerosis.

Recent Findings ${ }^{18} \mathrm{~F}-\mathrm{FDG}$ is an established measure of increased macrophage activity. However, due to its low specificity, new radiotracers have emerged for more specific detection of vascular inflammation and other high-risk plaque features such as microcalcification and neovascularization. Novel NIRF probes are engineered to sense endothelial damage as an early sign of plaque erosion as well as oxidized low-density lipoprotein (oxLDL) as a prime target for atherosclerosis. Integrated NIRF/OCT (optical coherence tomography) catheters enable to detect stent-associated microthrombi.

Summary Novel radiotracers can improve specificity of PET for imaging atherosclerosis. Advanced NIRF probes show promise for future application in human. Intravascular NIRF might play a prominent role in the detection of stent-induced vascular injury.
\end{abstract}

Keywords Atherosclerosis $\cdot$ Inflammation $\cdot$ Plaque $\cdot$ NIRF $\cdot$ PET

$\begin{array}{ll}\text { Abbreviations } \\ \text { BMS } & \text { Bare metal stent } \\ \text { BSV } & \text { Blood subtracted value } \\ \text { Cat } & \text { Cathepsin } \\ \text { CT } & \text { Computed tomography } \\ \text { DES } & \text { Drug eluting stent } \\ \text { FMT } & \text { Fluorescence-mediated molecular tomography } \\ \text { FRI } & \text { Fluorescence reflectance imaging } \\ \text { FDG } & \text { Fluorodeoxyglucose } \\ \text { ICG } & \text { Indocyanine green } \\ \text { MMP } & \text { Matrix-metalloprotease } \\ \text { MR } & \text { Magnetic resonance } \\ \text { NIRAF } & \text { Near-infrared autofluorescence } \\ \text { NIRF } & \text { Near-infrared fluorescence imaging } \\ \text { OCT } & \text { Optical coherence tomography }\end{array}$

This article is part of the Topical Collection on Nuclear Cardiology

Csilla Celeng

c.celeng@umcutrecht.nl

1 Department of Radiology and Nuclear Medicine, University Medical Center Utrecht, Heidelberglaan 100, 3584

CX Utrecht, The Netherlands

2 Heart and Vascular Center, Semmelweis University, Gaál József street 9, Budapest 1122, Hungary
OFDI Optical frequency domain imaging

OxLDL Oxidized low-density lipoprotein

PET Positron emission tomography

SSTR2 Somatostatin subtype-2 receptor

SUV Standardized uptake value

TBR Target to background ratio

VCAM-1 Vascular cell adhesion molecule-1

USPIO Ultrasmall superparamagnetic iron oxide

\section{Introduction}

Despite all prevention efforts, cardiovascular disease remains one of the leading global causes of death. In 2015, over 7 million deaths worldwide were attributable to the disease [1], which number is expected to rise to more than 23.6 million by 2030 [2]. Cardiovascular diseases encompass several pathological conditions such as coronary heart disease, stroke, and valvular diseases, which are commonly associated with the presence of atherosclerosis. Due to the destructive nature of atherosclerosis, advanced diagnostic imaging techniques have emerged for the detection and characterization of the condition.

Atherosclerosis is the result of a complex process of arterial wall thickening due to immune responses triggered by 
inherent genetic vulnerabilities and cardiovascular clinical risk factors. Atherosclerosis is most likely initiated by the damage of endothelial cells due to flow disturbances, which lead to over-expression of vascular cell adhesion molecule-1 (VCAM-1), which provokes recruitment of monocytes and T lymphocytes [3]. Monocytes infiltrate the intima and differentiate into macrophages, which becomes filled with lipids and transform to foam cells [4]. Persistent arterial inflammation leads to the proliferation of smooth muscle cells, which in normal circumstances are responsible for healing and repair of arterial injury [5]. Apoptosis of macrophages and smooth muscle cells contribute to plaque instability by promoting the development of a necrotic core [6], which is associated with an increased risk for plaque rupture [7]. Macrophages play a conductor role in the cellular orchestra of atherosclerosis and are therefore attractive targets for imaging.

Positron emission tomography (PET) is a non-invasive diagnostic imaging tool mainly used for cancer imaging, which also allows for the detection of active arterial inflammation. The usefulness of PET for vascular imaging has been successfully demonstrated in multiple studies, including cardiovascular drug trials where PET served as a proxy end point. PET signal correlates with macrophage density in carotid artery plaques [8], inflammatory biomarkers such as C-reactive protein [9] and also with cardiovascular risk factors and the Framingham risk score $[10,11]$. The fusion of PET with computed tomography (CT) enables detailed visualization of both functional and anatomical alterations in the atherosclerotic milieu, thus offering incremental prognostic information over PET alone.

Near-infrared fluorescence imaging (NIRF) is another widely investigated technique but as yet it has only been validated to a very limited extent in humans. NIRF uses fluorescent molecular structures (fluorophores) which are capable of biding to various molecular targets such as VCAM-1 molecules [12], oxidized LDL [13••], and smooth muscle cells [14 $]$ but most preferably they connect to macrophage expressed matrix-metalloproteases (MMPs) [15] and cathepsins (cysteine proteases), which initiate the degradation of elastin a structural component of the arterial wall. Besides their elastolytic activity, cathepsins were shown to degrade apolipoprotein B into lipid droplets hence they might play a pivotal role in the development of the lipid-rich necrotic core [16]. Intravascular NIRF uses a specific catheter for sensing intraarterial signs of atherosclerosis. The combination of NIRF catheter with high-resolution imaging techniques such as optical coherence tomography (OCT) or optical frequency domain imaging (OFDI) provides detailed functional and morphological information.

In the past decades, embedding anti-atherosclerotic medication into the medical regime of "vulnerable patients" has reshaped the course of the disease and the concept of vulnerable plaque-related thrombosis is now shifting towards plaque erosion initiated acute coronary syndrome. The development of state-of-the-art imaging techniques, which beyond the morphological signs of atherosclerosis are also able to detect changes in molecular activity, is of utmost importance. The inherent properties of PET and NIRF could fulfill these criteria; thus, in the future further refinement as well as increased use of these promising imaging methods is expected.

\section{PET Imaging of Atherosclerosis}

\section{Technical Aspects}

PET is a non-invasive imaging method, which can detect the activity of physiological and pathological processes in vivo. PET measures annihilation radiation, which occurs during radioactive decay of radiopharmaceutical tracers labeled with positron emitting radionuclides such as ${ }^{11} \mathrm{C},{ }^{13} \mathrm{~N},{ }^{15} \mathrm{O}$, and ${ }^{18} \mathrm{~F}$ (Table 1). The emitted positron annihilates with an electron, which leads to the release of two high-energy $(511 \mathrm{keV})$ photons [17]. Most PET scanners use scintillation detectors to identify the high-energy photons. The interaction of highenergy photons with the scintillation crystals creates tens of thousands of visible "scintillation" photons. These photons are captured by a photomultiplier tube, in which they are accelerated and amplified. Interaction of annihilation photons in the human tissue (Compton scatter) reduces their energy; thus, attenuation of the signal is a major determinant of the image quality of PET, which requires attenuation correction.

Due to its non-invasive nature and the ability to provide information on biological function PET has become a promising imaging method for the visualization of atherosclerotic processes. Activity of an atherosclerotic plaque is characterized by the accumulation of a given radiotracer. Uptake of the radiotracer can be quantified by its standardized uptake value (SUV), which represents the signal intensity of a voxel within the region of interest. Alternatively, target to background ratio (TBR, arterial wall SUV divided by venous blood SUV) or more recently blood subtracted value (BSV, arterial wall activity subtracted by venous blood activity) have been used for the quantification of arterial inflammation [18, 19]. Hybrid imaging with PET/CT and PET/magnetic resonance (MR) allows for accurate co-registration of metabolic processes to specific anatomic locations.

\section{PET Molecular Targets of Atherosclerosis}

\section{${ }^{18}$ F-FDG PET}

${ }^{18} \mathrm{~F}$-FDG is a glucose analogue, which has been linked with macrophage activity (Fig. 1) [20, 21]. Nevertheless, evaluating the coronaries with ${ }^{18} \mathrm{~F}$-FDG PET is still challenging, 
Table 1 Technical aspects and molecular imaging targets of PET and NIRF

\begin{tabular}{|c|c|c|}
\hline Imaging modality & PET & NIRF \\
\hline Operating articles & $\begin{array}{l}\text { - Positron emitting isotopes } \\
\left.\quad{ }^{11} \mathrm{C},{ }^{13} \mathrm{~N},{ }^{15} \mathrm{O},{ }^{18} \mathrm{~F}\right) \\
\text { - Isotope-labeled radiotracers } \\
\quad \text { (glucose, water, ammonia) }\end{array}$ & $\begin{array}{l}\text { - Fluorophores } \\
\text { - Proteins, peptides } \\
\text { small organic compounds } \\
\text { synthetic oligomers and polymers } \\
\text { multi-component systems }\end{array}$ \\
\hline Manner of Operation & $\begin{array}{c}\text { Annihilation of the emitted positron with } \\
\text { nearby electrons } \\
\downarrow \\
\text { radioactive decay }\end{array}$ & $\begin{array}{c}\text { Absorption of light energy of specific } \\
\text { wavelength ( } 700-900 \mathrm{~nm}) \text { and re- } \\
\text { emission of photons at a longer } \\
\text { wavelength } \\
\downarrow \\
\text { fluorescence }\end{array}$ \\
\hline Emission & $\begin{array}{l}\text { Single event: } 2 \text { high-energy photons } \\
\quad(511 \mathrm{keV})\end{array}$ & $\begin{array}{l}\text { Cyclic event: } 10^{9} \text { photons } / \mathrm{s} \\
(1.91-1.38 \mathrm{eV})\end{array}$ \\
\hline Event localization & $\begin{array}{l}\text { Scintillation detector and photo } \\
\text { multiplier tube }\end{array}$ & CCD camera \\
\hline Attenuation in the body & $\begin{array}{l}\text { Compton scatter: annihilation photons } \\
\text { are attenuated depending on the density } \\
\text { on the tissue (the more dense the more } \\
\text { attenuated) }\end{array}$ & $\begin{array}{l}\text { Deep tissue penetration, diffuse } \\
\text { propagation }\end{array}$ \\
\hline $\begin{array}{l}\text { Quantification of molecular } \\
\text { activity }\end{array}$ & $\begin{array}{l}\text { - SUV; signal intensity of a voxel } \\
\text { within the region of interest } \\
\text { - TBR; arterial wall SUV divided by } \\
\text { venous blood SUV } \\
\text { - BSV; arterial wall activity } \\
\text { subtracted by venous blood activity }\end{array}$ & - Wavelength in nanometers \\
\hline Disadvantage & $\begin{array}{l}\text { - Strong attenuation in the body, } \\
\text { requires attenuation correction } \\
\text { - Radiation exposure }\end{array}$ & $\begin{array}{l}\text { - Autofluorescence } \\
\text { - Intravascular NIRF is an } \\
\text { invasive procedure }\end{array}$ \\
\hline Imaging agents and targets & $\begin{array}{l}-{ }^{18} \mathrm{~F}-\mathrm{FDG} \text { PET-macrophages } \\
-{ }^{18} \mathrm{~F}-\mathrm{NaF} \text { PET-calcification } \\
-{ }^{68} \mathrm{Ga} \text {-DOTATATE-SSTR2 } \\
\text { receptors (macrophages) } \\
-{ }^{68} \text { Ga-PENTAXIFOR-CXCR4 } \\
\text { receptors (macrophages) }\end{array}$ & $\begin{array}{l}\text { - ProSense } 680 \text { and } 750- \\
\text { cathepsins B, L, S, and K } \\
\text { - MMPSense } 680 \text { and GelSense } \\
\text { 680-MMP activity } \\
\text { - OsteoSense 680-calcium } \\
\text { deposition } \\
\text { - CLIO-CyAm7 USPIO } \\
\text { nanoparticle- macrophages, } \\
\text { smooth muscle cells, } \\
\text { endothelial cells, thrombosed } \\
\text { plaques } \\
\text { - LO1-750-oxidized LDL } \\
\text { - ICG macrophages and foam } \\
\text { cells }\end{array}$ \\
\hline
\end{tabular}

SUV standardized uptake value, $T B R$ tissue-to-background ratio, $B S V$ blood subtracted value, $U S P I O$ ultrasmall superparamagnetic iron oxide, $I C G$ indocyanine green

owing to their small size and constant motion. Due to limited spatial resolution $(\approx 5 \mathrm{~mm})$ of PET scanners, the measured arterial activity is affected by signal loss to surrounding tissue (spill out) and signal added from neighboring structures (spill in, mainly due to blood activity) [22••]. Background myocardial FDG uptake can be suppressed using a high-fat, lowcarbohydrate diet [23]. The ${ }^{18}$ F-FDG circulation time has to be long enough to allow for sufficient FDG accumulation in areas of interest compared to background levels; nevertheless, it has to be as short as possible to allow for efficient workflow and patient comfort. In oncology, a 60-min time slot is commonly used, while in vascular imaging 180 min provides improved quantification [24•]. ${ }^{18}$ F-FDG provides reproducible measures and can be also used to evaluate the effectiveness of antiatherosclerotic therapies $[25,26]$. For example, ${ }^{18}$ F-FDG PET can differentiate the effect of high- vs. low-dose statins on the degree of atherosclerotic inflammation [26].

\section{${ }^{18}$ F-NaF PET}

Calcification is a hallmark feature of atherosclerosis and CT is widely used to detect macroscopic calcium in the coronary artery tree (i.e., coronary artery calcium/Agatston score), though its triggers remain matter of debate. ${ }^{18} \mathrm{~F}$-sodium 


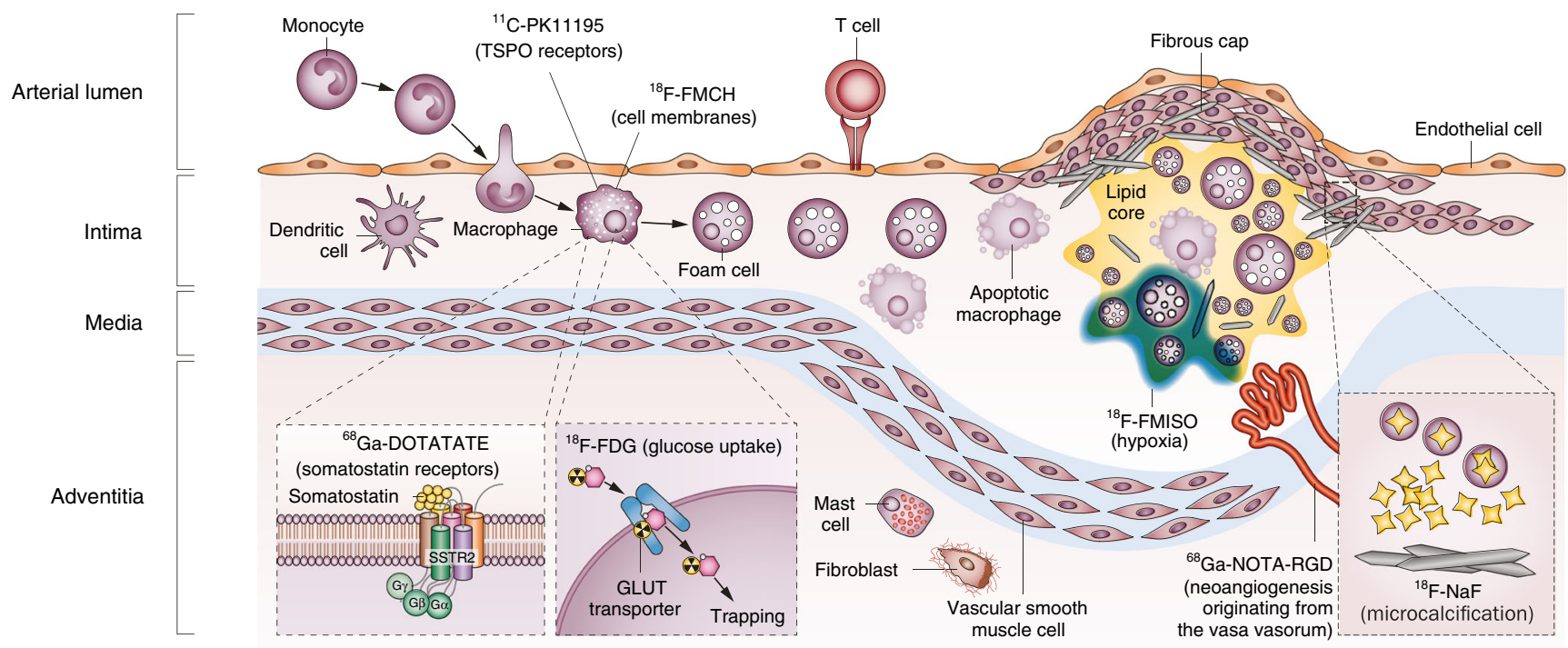

Fig. 1 Potential targets for radiotracers in PET imaging of atherosclerosis. Inflammation and underlying pathological mechanisms within high-risk plaques can be detected in vivo by using specific PET tracers. ${ }^{18} \mathrm{~F}-\mathrm{FDG}$ is the most widely investigated and validated PET tracer, which is internalized by macrophages and accumulates proportional to their metabolic activity. The signal of ${ }^{18} \mathrm{~F}$-FDG might however be influenced by other factors such as local hypoxia or uptake by cells other than macrophages. Novel PET tracers including ${ }^{68} \mathrm{Ga}-$ DOTATATE, ${ }^{1} \mathrm{C}-\mathrm{PK} 11195$, and ${ }^{18} \mathrm{~F}-\mathrm{FMCH}$ might be more specific for activated macrophages than ${ }^{18} \mathrm{~F}$-FDG. Other pathological processes including hypoxia, microcalcification, and neoangiogenesis also contribute to the evolution of vulnerable plaque. These processes can be potentially identified with other novel traces such as ${ }^{18} \mathrm{FMISO},{ }^{68} \mathrm{Ga}$ NOTA-RGD, and ${ }^{18} \mathrm{~F}-\mathrm{NaF}$. DOTATATE, $[1,4,7,10-$ tetraazacyclododecane- $N, N^{\prime}, N^{\prime \prime}, N^{\prime \prime \prime}$-tetraacetic acid]-D-Phe ${ }^{1}, \mathrm{Tyr}^{3}$ octreotate; FDG, fluorodeoxyglucose; FMCH, fluoromethylcholine; FMISO, fluoromisonadazole; GLUT, solute carrier family 2, facilitated glucose transporter member; NaF, sodium fluoride; NOTA-RGD, 1,4,7triazacyclononane-1,4,7-triacetic acid-Arg-Gly-Asp; SSTR2, somatostatin receptor type 2; TSPO, translocator protein. (Reprinted with permission from Macmillan Publishers Ltd: Nat Rev Cardiol [21], (C) 2014) fluoride $\left({ }^{18} \mathrm{~F}-\mathrm{NaF}\right)$ PET has been used as a bone tracer. At the molecular level, fluoride ions interact with hydroxyapatite by ion exchange with hydroxyl groups [27] and uptake of ${ }^{18} \mathrm{~F}$ $\mathrm{NaF}$ is linked with osteogenic activity. In the context of atherosclerotic plaque imaging, ${ }^{18} \mathrm{~F}-\mathrm{NaF}$ has been used as an in vivo marker of active calcification $[28,29] .{ }^{18} \mathrm{~F}-\mathrm{NaF}$ is thus capable of detecting early stages of atherosclerosis, namely dedifferentiation of smooth muscle cells resulting in neointimal (micro)calcification (Fig. 1) [21]. Moreover, Dweck et al. [28] observed increased ${ }^{18} \mathrm{~F}-\mathrm{NaF}$ activity only in the culprit lesion, which is thought to reflect subclinical plaque rupture.

\section{${ }^{68}$ Ga-DOTATATE PET}

${ }^{68} \mathrm{Ga}$-DOTATATE is a novel PET tracer, which has been mainly applied for the detection of neuroendocrine neoplasms, which express somatostatin receptors [30]. ${ }^{68} \mathrm{Ga}$ DOTATATE has high specificity binding affinity for activated macrophages through the somatostatin subtype-2 receptor (SSTR2) [21, 31] (Fig. 1), as such it can be superior to FDG. In mice, ${ }^{68} \mathrm{Ga}$-DOTATATE uptake co-localized with macrophage-rich plaques on immunohistochemical staining [32]. Recently, Tarkin et al. [33] evaluated ${ }^{68}$ Ga-DOTATATE in 42 patients with atherosclerosis. They demonstrated that SSTR2 gene expression is specific for activated proinflammatory macrophages in atherosclerosis and thus ${ }^{68}$ Ga-DOTATATE was capable of identifying culprit vs. nonculprit lesions in patients with acute coronary syndrome. Somatostatin receptors can be also imaged with ${ }^{68} \mathrm{Ga}$ DOTANOC, which besides SSTR2 can bind to SSTR3 and SSTR5 [30]. Despite the coverage of other somatostatin receptor types, ${ }^{68} \mathrm{Ga}$-DOTANOC shows lower signal intensity compared to ${ }^{68} \mathrm{Ga}$-DOTATATE [34].

\section{${ }^{68}$ Ga-PENTAXIFOR PET}

${ }^{68} \mathrm{Ga}$-PENTAXIFOR has been recently introduced as a PET imaging agent in patients with lymphoproliferative disease [35]. ${ }^{68} \mathrm{Ga}$-PENTAXIFOR shows high affinity to CXCR4 receptors [36], which are expressed by various inflammatory cells including macrophages/monocytes and smooth muscle cells. Targeted imaging with ${ }^{68}$ Ga-PENTAXIFOR was able to identify regional upregulation of CXCR4 receptors in infarcted myocardium of mice and human as well [37••]. In a recent in-human study, ${ }^{68} \mathrm{Ga}$-PENTAXIFOR showed significant association with calcified plaque burden and other cardiovascular risk factors [38••]. Due to its high specificity in the near future, the incorporation of ${ }^{68} \mathrm{Ga}$-PENTAXIFOR to preclinical and clinical studies focusing on atherosclerosis is expected. 


\section{NIRF Imaging of Atherosclerosis}

\section{Technical Aspects}

In the past two decades owing to its high sensitivity and resolution as well as absence of radiation, NIRF has emerged as a promising imaging modality for the visualization of atherosclerosis. NIRF is based on fluorescence optical imaging method that uses excitation light from the near-infrared spectrum $(700-900 \mathrm{~nm})$ to stimulate fluorescent molecules (fluorophores, contrast agents for NIRF) from ground state $\left(\mathrm{S}_{0}\right)$ to an excited $\left(\mathrm{S}_{1}, \mathrm{~S}_{2}\right)$ state [39]. Relaxation of this excited state to a lower energetic state results in the emission of fluorescence light at longer wavelength. After reaching the ground state, the fluorophore is again available for a new excitation. This highly repetitive action leads to an emission of $10^{9}$ photons per second per molecule. Inherent properties of near-infrared light such as low absorption and high scattering characteristics allow for deep tissue penetration (to several centimeters) and diffuse expansion [40]. In addition, excitation with nearinfrared light in the region of $>750 \mathrm{~nm}$ considerably reduces undesired tissue autofluorescence [41] and by improving signal-to-background ratio makes NIRF a highly sensitive imaging tool.

The two most common approaches to detect fluorophores using near-infrared light in deep tissues are fluorescence reflectance imaging (FRI) and fluorescence-mediated molecular tomography (FMT). FRI consists of a laser or a white light source, which excites a fluorescent structure that emits light with different spectral properties and which is eventually captured by a CCD camera. Multi-channel FRI allows for simultaneous detection of different fluorochromes in multiple targets by using suitable filters in front of the CCD camera, which can selectively obtain images with different spectra [42]. FRI is most commonly applied for the visualization of cathepsin B [43], cathepsin K [44], and MMP activity [43].

FMT is the second approach to identify fluorescent contrast agents. It enables isotopic detection as well as absolute quantification of the given fluorophore [45]. The principles of FMT are similar to those in FRI, however, with more profound data collection: generally light from a laser diode is directed through optical fibers to the "optical bore" that surrounds the body of the animal and serves as a CT or MR scanner during the examination. Detection fibers collect the emitted photons and direct them onto CCD camera. FMT can be combined with high-resolution imaging techniques such as $\mathrm{CT}$ or MR in order to refine anatomical features [46, 47]. Besides cathepsin B [48], FMT is able to visualize MMP activity [49] as well as fluorescence autoantibodies [13••].
NIRF Molecular Targets of Atherosclerosis

Increasing knowledge of the pathogenesis of atherosclerosis allows for the identification of novel molecular and structural imaging targets. NIRF molecular imaging of atherosclerotic mechanisms involves the administration of near-infrared fluorophores, which aim to detect and quantify high-risk features of atherosclerosis such as cathepsins $\mathrm{S}, \mathrm{K}, \mathrm{B}, \mathrm{L}$, and F, which are most commonly expressed by macrophages and smooth muscle cells in atherosclerotic plaques [16-18]. One of the most widely investigated NIRF imaging agent in animal studies is ProSense (680 and 750), a copolymer-based smart probe, which is optically silent at baseline (unactivated) and becomes highly fluorescent (activated) after cathepsins B, L, or S protease-mediated cleavage. Using the FRI technique, the cathepsin-activated contrast dye showed strong signal enhancement in macrophage-rich atherosclerotic lesions at the level of the aortic valves in hypercholesterolemic apolipoprotein E-deficient (apoE-/- mice) [43]. By linking a specific cathepsin K (CatK)-sensitive substrate to the copolymer, this NIRF contrast agent is rather cleaved by CatK instead of CatB [44]. Imaging of CatK is of importance as it preferentially colocalizes in macrophages [44] and in vulnerable areas of atherosclerotic lesions, such as the thin fibrous cap, plaque shoulders but it was also detected in ruptured plaques indicating its potential plaque-destabilizing role $[44,50]$. Besides cathepsins elevated MMP activity was demonstrated to be strongly associated with unstable atherosclerotic plaques [51, 52]. Gelatinases (such as GelSense 680 or MMPSense 680) are metalloproteinase activatable florescent imaging agents, which demonstrate increased NIRF signal after MMPmediated activation predominantly released by macrophages rather than smooth muscle or endothelial cells [43, 49]. NIRF imaging of gelatin zymography was also able to differentiate hot and cold spots (areas with relatively high and low signal intensity) across the plaque surface which might indicate the presence of lesion instability [15]. Monitoring vascular response after stent implantation is also feasible with MMP activated fluorochromes. FMT analysis showed significantly increased MMP activity in stented aortas of apoE $\mathrm{E}^{-/-}$mice compared to wild-type (WT) mice [53]. These findings were also confirmed by real-time PCR, which revealed significantly more transcripts encoding for MMP-2, MMP-9, and MMP-13 in apo: $\mathrm{E}^{-/-}$mice than those in WT mice. Other atherosclerotic processes such as increased osteoblastic activity as an early precursor of calcium deposition can be also targeted by fluorescent bisphosphonate imaging agents (OsteoSense 680) [43].

As the focus from thin fibrous cap rupture shifts towards superficial erosion related plaque thrombosis [54••], novel imaging targets emerge for the visualization of the associated pathological mechanisms. Endothelial cell damage induced by shear stress leads to the development of impaired 
endothelial permeability and may indicate future presentation of superficial erosion [55]. To address this hypothesis a CLIOCyAm7 a NIRF-derivatized ultrasmall superparamagnetic iron oxide (USPIO) nanoparticle was engineered and applied in rabbits on high-cholesterol diet [14•]. CLIO-CyAm7 accumulated in atherosclerotic plaques, primarily in the superficial intima within macrophages, smooth muscle cells, endothelial cells, and thrombosed lesions. Heterogeneous distribution of CLIO-CyAm7 across the plaque surface as well as its deposition in deeper areas with neovascularization indicated regional alterations in endothelial permeability. CLIO-CyAm7 USPIO nanoparticle therefore might be useful for the detection of high-risk atheroma as well as early signs of superficial erosion.

State-of-the are NIRF dye-labeled monoclonal autoantibodies aim to identify and quantify oxidized low-density lipoprotein (oxLDL) as prime target of atherosclerosis. Specifically, in a recent study LO1 monoclonal autoantibody (which is able to react with oxLDL) was labeled with NIRF dye (LO1-750) and its uptake was analyzed in high fed (HF) atherosclerotic $\mathrm{LDLr}^{-/}$mice and WT mice [13••] on FMT-CT images. In addition, the signal activity of LO1-750 was compared to MMP-activatable (MMPSense-645-FAST) fluorescent probe. After the injection of LO1-750 into $\mathrm{LDLr}^{-/-}$mice, a clear accumulation was observed in the aortic arch and its branches. Quantitative analysis of LO1-750 revealed a significantly higher uptake by $\mathrm{LDLr}^{-1}$ mice compared to WT mice $(25.3 \pm 4.6$ vs. $1.3 \pm 0.9$ pmol; $P<0.005)$. LO-750 in $\mathrm{LDLr}^{-/-}$ to WT mice gave superior signal ratio comparing to MMPSense (19.3 vs. $2.8, P=0.03$ ). Furthermore, a generated partially humanized chimeric LO1-Fab-Cys-750 construct localized similarly to the parent antibody in mice atherosclerotic lesion showing potential for future application in humans $[13 \bullet \bullet]$.

The use of NIRF imaging for the visualization of atherosclerosis is mainly limited due to lack of clinically approved fluorophores for human use. To date, indocyanine green (ICG) is the only US Food and Drug Administration-approved contrast agent that can be employed for the evaluation of hepatic function [56], cardiac output [57], and retinal angiography [58] on the basis of its dark green color. ICG is an amphiphilic contrast dye (it has both hydrophilic and lipophilic properties) and is able to interact rapidly with HDL and LDL [59]. Furthermore, it showed reliable detection of inflammatory alterations in arthritis [60]. Owing to these characteristics in the past decade, the capability of ICG to identify inflamed atherosclerotic lesions was intensively investigated. A study by Vinegoni et al. [61] demonstrated that ICG primarily accumulates in lipid and macrophage-rich areas of atherosclerotic plaques in rabbits. In the in vitro part of the study, they also showed that through direct binding to LDL or albumin human macrophages and foam cells are also able to internalize ICG.
With the use of a combined OCT-NIRF technique, the same group conducted the first-in-human trial, which aimed to visualize atherosclerotic lesions in patients prior to carotid endarterectomy with the administration of ICG [62 •]. OCTNIRF of the resected carotid portions detected evident ICG signals in all patients injected with ICG with higher signal intensity of extensively stenotic vessels.

\section{NIRF Intravascular Imaging of Atherosclerosis}

In 2008, Farouc et al. [63] developed a NIRF catheterbased imaging technique to detect intravascular sings of atherosclerosis in vivo. The catheter was designed to sense fluorescence signal of an area of $\approx 40 \mu \mathrm{m}$ diameter with a distance of $\approx 2 \mathrm{~mm}$ from the catheter, however, without rotation and pullback function thus was operating in a one-dimensional manner. The developed $90^{\circ}$-sense catheter was able to detect NIRF signals attributable to cysteine protease, specifically cathepsin B activity in rabbit iliac arteries. The same group later addressed the limitations of this catheter and in 2011 developed a two-dimensional rotational NIRF catheter, with automatic pullback function in order to provide new insights to arterial inflammation and stent healing process in vivo [64]. The $2 \mathrm{D}$ intravascular NIRF catheter was able to provide real-time images of cathepsin $\mathrm{B}$ activity as well as of elevated signal levels at the distal edges of the implanted stents, which might suggest that in the injured vessels the damage presents at sharp transition zones. The capability of NIRF for the detection of stent-induced vascular injury might elucidate the confusing data over bare metal stents vs. drug eluting stentassociated events [65-67].

NIRF imaging was also combined with high-resolution imaging techniques such as OFDI, which owing to its highresolution and high frame-rate is able to visualize the detailed three-dimensional microstructure of the arterial wall [68]. An engineered hybrid NIRF-OCDI catheter allowed for concomitant assessment of molecular and microstructural characteristics of high-risk plaques and stent thrombosis in rabbits in vivo (Fig. 2) [69]. One of the limitations of the dualmodality NIRF-OCDI imaging is the manual adjustment of the detected NIRF map with the corresponding OFDI vessel wall position, which is a time-consuming process. To overcome this obstacle, a fully automated algorithm was developed and validated in previously manually segmented rabbit and human artery images [70]. Results showed high similarity correlation between the manual and fully automatic method as well as greatly reduced processing time ( $44 \mathrm{~ms}$ vs. $1 \mathrm{~h}$ or more), suggesting that more frequent interpretation of NIRFOCDI in the future is expected. 
Fig. 2 Integrated OFDI-NIRF images of a rabbit iliac artery with an implanted NIRF fibrin-coated stent, attained in vivo. a OFDI (gray scale) with thrombus segmentation (purple). b OFDI (gray scale)-NIRF (yellow scale) overlaid images. c Corresponding HE histology images. Middle rows demonstrate zoomed images of the thrombus (red arrow), stent struts (yellow asterisks, black asterisks in HE images), and their shadow (white asterisk). Bottom rows show zoomed images of an area (red arrowheads), which was thrombus negative according to OFDI; however, NIRF detected a weaker fluorescence signal, which was also confirmed by histology. d Three-dimensional image of a stented right iliac artery of a living rabbit. Structural components were segmented and color-coded in OFDI images for clear visualization. Red: artery wall; white: stent; purple: thrombus; yellow: near-infrared fluorescent fibrin. Scale bars, $500 \mu \mathrm{m}$. (Reprinted with permission from Macmillan Publishers Ltd: Nat Med [69], (C) 2011)

\section{OFDI thrombus segmentation}

a
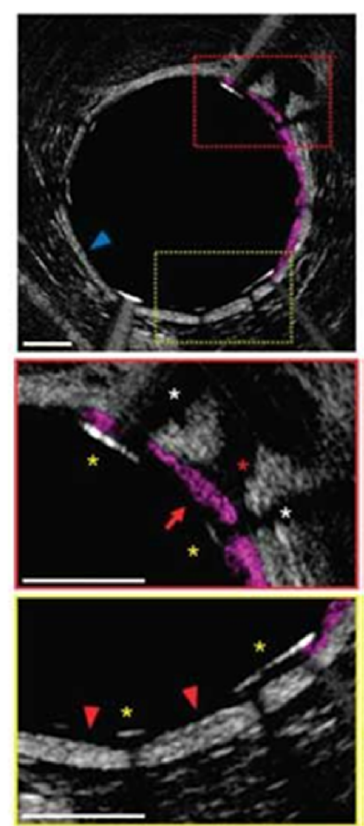

d

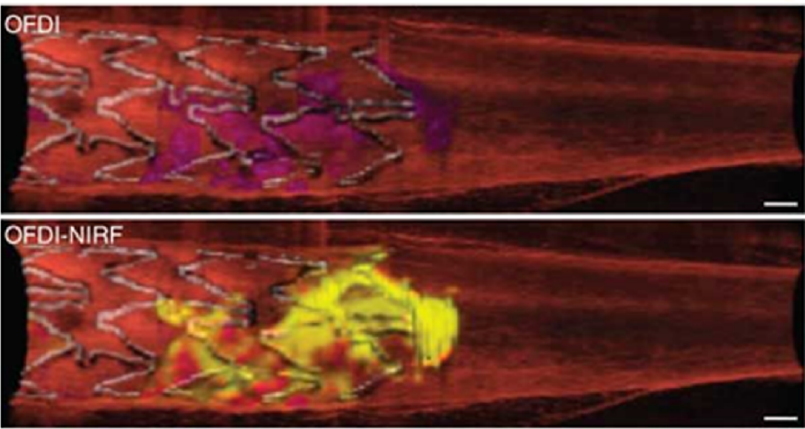

HE histology

b
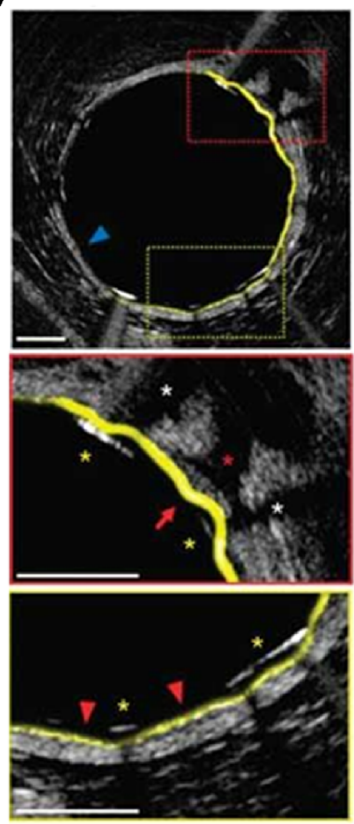

C
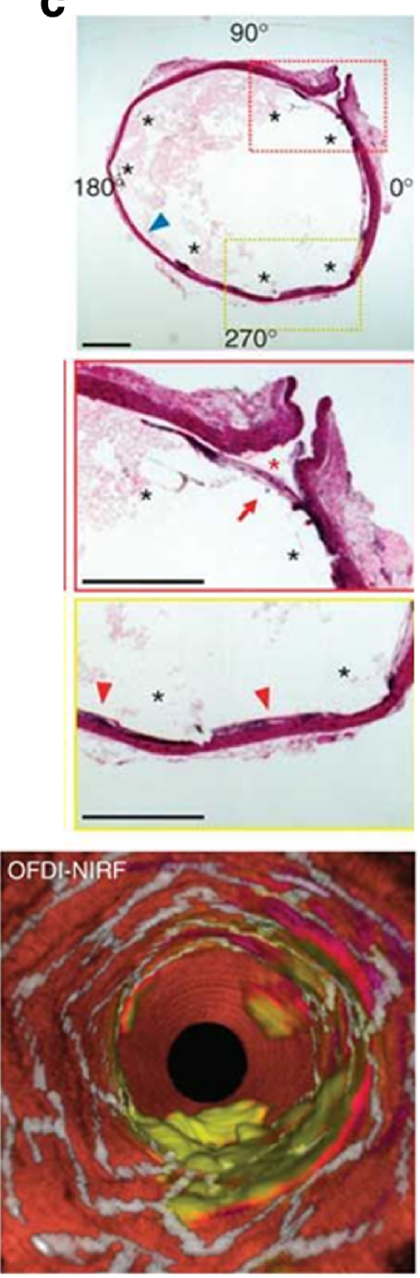

Previous studies by Lee et al. [71•] demonstrated the feasibility of real-time structural/molecular imaging by combining OCT data with NIRF. The integrated OCT-NIRF catheter was able to simultaneously co-localize the morphological and pathological alterations of rabbit atherosclerotic plaques targeted with ICG exogenous contrast dye [71•]. One step further, the same group also showed the capability of the integrated OCT-NIRF catheter to identify high-risk plaques and stent-related inflammation in beating swine coronary arteries [72].

Recently, red excited $(633 \mathrm{~nm})$ near-infrared autofluorescence (NIRAF) is another profoundly investigated imaging method [73], as it does not require the administration of exogenous contrast agent, which property might facilitate its early adoption in the clinical routine. The incorporation of NIRAF with OCT was able to provide high-quality imaging data of coronary atherosclerotic lesions in patients undergoing percutaneous coronary angiography [74•]. An increased NIRAF signal was significantly associated with thin-cap fibroatheroma and plaque rupture defined by OCT.

\section{Conclusions}

Current approach to personalized medicine resulted in advanced imaging tools for the evaluation of atherosclerosis. These new imaging techniques will further enhance our understanding of the disease mechanisms. PET imaging allows for the direct visualization of metabolic processes, including plaque inflammation, bone formation, as well as macrophage activity, which is already widely studied in humans. Besides the tracers discussed in this review, novel ${ }^{18} \mathrm{~F}$-labeling methods will enable the synthesis of specifically labeled PET tracers, thus enabling more specific assessment of in vivo pharmacokinetics.

NIRF molecular imaging agents are designed to reveal premature signs of atherosclerosis on a molecular level and have potential to identify individuals who might benefit from early preventive therapy. NIRF is however still in investigational phase and its use in clinical practice will require long-term clinical trials. It is expected that in the near future, state-ofthe-art fluorophores with desirable architecture such as high 
solubility and photon emission will be validated in humans. Intravascular NIRF molecular imaging especially OFDINIRF or OCT-NIRF platforms are capable to provide realtime microscopy-resolution images of molecular as well as structural changes of the arterial wall. Beyond identifying high-risk features of atherosclerosis, NIRF intravascular molecular imaging is also able to assess response to implanted stents including potential thrombotic apposition, therefore, might play a prominent role in adjustment of the applied medical regimens such as antiplatelet and statin therapy. In addition, the use of automatic algorithms for image processing can greatly contribute to its faster clinical utilization.

\section{Compliance with Ethical Standards}

Conflict of Interest Bart de Keizer, Béla Merkely, Pim de Jong, Tim Leiner, and Richard A.P. Takx declare that they have no conflict of interest.

Csilla Celeng reports grant support from the European Association of Cardiovascular Imaging (EACVI).

Human and Animal Rights and Informed Consent This article does not contain any studies with human or animal subjects performed by any of the authors.

Open Access This article is distributed under the terms of the Creative Commons Attribution 4.0 International License (http:// creativecommons.org/licenses/by/4.0/), which permits unrestricted use, distribution, and reproduction in any medium, provided you give appropriate credit to the original author(s) and the source, provide a link to the Creative Commons license, and indicate if changes were made.

\section{References}

Papers of particular interest, published recently, have been highlighted as:

- Of importance

•. Of major importance

1. Organization WH (2015) Cardiovascular diseases (CVDs). Available via http://www.who.int/mediacentre/factsheets/fs317/en/. Accessed Augus 10, 2017.

2. Organization WH global status report on noncommunicable diseases 2010. Geneva, Switzerland. Available via http://www.who. int $/ \mathrm{nmh} /$ publications/ncd_report_full_en.pdf. Accessed August 10, 2017.

3. Falk E. Pathogenesis of atherosclerosis. J Am Coll Cardiol. 2006;47(8 Suppl):C7-12. https://doi.org/10.1016/j.jacc.2005.09.068.

4. Mantovani A, Garlanda C, Locati M. Macrophage diversity and polarization in atherosclerosis: a question of balance. Arterioscler Thromb Vasc Biol. 2009;29(10):1419-23. https://doi.org/10.1161/ ATVBAHA.108.180497.

5. Doran AC, Meller N, Mcnamara CA. Role of smooth muscle cells in the initiation and early progression of atherosclerosis. Arterioscler Thromb Vasc Biol. 2008;28(5):812-9. https://doi.org/ 10.1161/ATVBAHA.107.159327.

6. Moore KJ, Tabas I. Macrophages in the pathogenesis of atherosclerosis. Cell. 2011;145(3):341-55. https://doi.org/10.1016/j.cell. 2011.04.005.
7. Virmani R, Burke AP, Farb A, Kolodgie FD. Pathology of the vulnerable plaque. J Am Coll Cardiol. 2006;47(8 Suppl):C13-8. https://doi.org/10.1016/j.jacc.2005.10.065.

8. Tawakol A, Migrino RQ, Bashian GG, Bedri S, Vermylen D, Cury $\mathrm{RC}$, et al. In vivo $18 \mathrm{~F}$-fluorodeoxyglucose positron emission tomography imaging provides a noninvasive measure of carotid plaque inflammation in patients. J Am Coll Cardiol. 2006;48(9): 1818-24. https://doi.org/10.1016/j.jacc.2006.05.076.

9. Yoo HJ, Kim S, Park MS, Yang SJ, Kim TN, Seo JA, et al. Vascular inflammation stratified by C-reactive protein and low-density lipoprotein cholesterol levels: analysis with $18 \mathrm{~F}-\mathrm{FDG}$ PET. J Nucl Med. 2011;52(1):10-7. https://doi.org/10.2967/jnumed.110. 080838 .

10. Noh TS, Moon SH, Cho YS, Hong SP, Lee EJ, Choi JY, et al. Relation of carotid artery $18 \mathrm{~F}-\mathrm{FDG}$ uptake to C-reactive protein and Framingham risk score in a large cohort of asymptomatic adults. J Nucl Med. 2013;54(12):2070-6. https://doi.org/10.2967/ jnumed.113.119602.

11. Kim TN, Kim S, Yang SJ, Yoo HJ, Seo JA, Kim SG, et al. Vascular inflammation in patients with impaired glucose tolerance and type 2 diabetes: analysis with $18 \mathrm{~F}$-fluorodeoxyglucose positron emission tomography. Circ Cardiovasc Imaging. 2010;3(2):142-8. https:// doi.org/10.1161/CIRCIMAGING.109.888909.

12. Nahrendorf M, Jaffer FA, Kelly KA, Sosnovik DE, Aikawa E, Libby $\mathrm{P}$, et al. Noninvasive vascular cell adhesion molecule-1 imaging identifies inflammatory activation of cells in atherosclerosis. Circulation. 2006;114(14):1504-11. https://doi.org/10.1161/ CIRCULATIONAHA.106.646380.

13.• Khamis RY, Woollard KJ, Hyde GD, Boyle JJ, Bicknell C, Chang $\mathrm{SH}$, et al. Near infrared fluorescence (NIRF) molecular imaging of oxidized LDL with an autoantibody in experimental atherosclerosis. Sci Rep. 2016;6(1):21785. Relevant NIRF study, which demonstrates the feasibility of a NIRF dye-labeled autoantibody to detect oxidized LDL as a prime target of atherosclerosis. https:// doi.org/10.1038/srep21785.

14. Stein-Merlob AF, Hara T, Mccarthy JR, et al., Atheroma Susceptible to Thrombosis Exhibit Impaired Endothelial Permeability In Vivo as Assessed by Nanoparticle-Based Fluorescence Molecular Imaging. Circ Cardiovasc Imaging. 2017;10(5). A study about a NIRF-derivatized nanoparticle, which identifies decreased endothelial permeability as an early sign of superficial erosion.

15. Wallis De Vries BM, Hillebrands JL, Van Dam GM, et al. Images in cardiovascular medicine. Multispectral near-infrared fluorescence molecular imaging of matrix metalloproteinases in a human carotid plaque using a matrix-degrading metalloproteinase-sensitive activatable fluorescent probe. Circulation. 2009;119(20):e534-6. https://doi.org/10.1161/CIRCULATIONAHA.108.821389.

16. Oorni K, Sneck M, Bromme D, et al. Cysteine protease cathepsin F is expressed in human atherosclerotic lesions, is secreted by cultured macrophages, and modifies low density lipoprotein particles in vitro. J Biol Chem. 2004;279(33):34776-84. https://doi.org/10. 1074/jbc.M310814200.

17. Kinahan PE, Hasegawa BH, Beyer T. X-ray-based attenuation correction for positron emission tomography/computed tomography scanners. Semin Nucl Med. 2003;33(3):166-79. https://doi.org/ 10.1053/snuc.2003.127307.

18. Blomberg BA, Thomassen A, De Jong PA, et al. Impact of personal characteristics and technical factors on quantification of sodium 18F-fluoride uptake in human arteries: prospective evaluation of healthy subjects. J Nucl Med. 2015;56(10):1534-40. https://doi. org/10.2967/jnumed.115.159798.

19. Chen W, Dilsizian V. PET assessment of vascular inflammation and atherosclerotic plaques: SUV or TBR? J Nucl Med. 2015;56(4): 503-4. https://doi.org/10.2967/jnumed.115.154385. 
20. Hiari N, Rudd JH. FDG PET imaging and cardiovascular inflammation. Curr Cardiol Rep. 2011;13(1):43-8. https://doi.org/10. 1007/s11886-010-0150-5.

21. Tarkin JM, Joshi FR, Rudd JH. PET imaging of inflammation in atherosclerosis. Nat Rev Cardiol. 2014;11(8):443-57. https://doi. org/10.1038/nrcardio.2014.80.

22.• Huet P, Burg S, Le Guludec D, Hyafil F, Buvat I. Variability and uncertainty of $18 \mathrm{~F}-\mathrm{FDG}$ PET imaging protocols for assessing inflammation in atherosclerosis: suggestions for improvement. J Nucl Med. 2015;56(4):552-9. A relevant summary, which describes the variability of 18F-FDG PET measurements. https://doi.org/10.2967/ jnumed.114.142596.

23. Wykrzykowska J, Lehman S, Williams G, Parker JA, Palmer MR, Varkey S, et al. Imaging of inflamed and vulnerable plaque in coronary arteries with 18F-FDG PET/CT in patients with suppression of myocardial uptake using a low-carbohydrate, high-fat preparation. J Nucl Med. 2009;50(4):563-8. https://doi.org/10.2967/ jnumed.108.055616.

24. Blomberg BA, Thomassen A, Takx RA, et al. Delayed (1)(8)Ffluorodeoxyglucose PET/CT imaging improves quantitation of atherosclerotic plaque inflammation: results from the CAMONA study. J Nucl Cardiol. 2014;21(3):588-97. This study shows that delayed 18F-FDG PET imaging improves quantification of atherosclerotic plaque inflammation. https://doi.org/10.1007/ s12350-014-9884-6.

25. Rudd JH, Myers KS, Bansilal S, et al. (18)Fluorodeoxyglucose positron emission tomography imaging of atherosclerotic plaque inflammation is highly reproducible: implications for atherosclerosis therapy trials. J Am Coll Cardiol. 2007;50(9):892-6. https://doi. org/10.1016/j.jacc.2007.05.024.

26. Tawakol A, Fayad ZA, Mogg R, Alon A, Klimas MT, Dansky H, et al. Intensification of statin therapy results in a rapid reduction in atherosclerotic inflammation: results of a multicenter fluorodeoxyglucose-positron emission tomography/computed tomography feasibility study. J Am Coll Cardiol. 2013;62(10):90917. https://doi.org/10.1016/j.jacc.2013.04.066.

27. Joshi NV, Vesey A, Newby DE, Dweck MR. Will 18F-sodium fluoride PET-CT imaging be the magic bullet for identifying vulnerable coronary atherosclerotic plaques? Curr Cardiol Rep. 2014;16(9):521. https://doi.org/10.1007/s11886-014-0521-4.

28. Dweck MR, Chow MW, Joshi NV, et al. Coronary arterial $18 \mathrm{~F}$-sodium fluoride uptake: a novel marker of plaque biology. J Am Coll Cardiol. 2012;59(17):1539-48. https://doi.org/10.1016/j.jacc.2011.12.037.

29. Oliveira-Santos M, Castelo-Branco M, Silva R, Gomes A, Chichorro $\mathrm{N}$, Abrunhosa A, et al. Atherosclerotic plaque metabolism in high cardiovascular risk subjects - a subclinical atherosclerosis imaging study with 18F-NaF PET-CT. Atherosclerosis. 2017;260:41-6. https://doi.org/10.1016/j.atherosclerosis.2017.03.014.

30. Bozkurt MF, Virgolini I, Balogova S, Beheshti M, Rubello D, Decristoforo C, et al. Guideline for PET/CT imaging of neuroendocrine neoplasms with $68 \mathrm{Ga}$-DOTA-conjugated somatostatin receptor targeting peptides and 18F-DOPA. Eur J Nucl Med Mol Imaging. 2017;44(9):1588-601. https://doi.org/10.1007/s00259-017-3728-y.

31. Reubi JC, Schar JC, Waser B, et al. Affinity profiles for human somatostatin receptor subtypes SST1-SST5 of somatostatin radiotracers selected for scintigraphic and radiotherapeutic use. Eur J Nucl Med. 2000;27(3):273-82. https://doi.org/10.1007/ s002590050034.

32. Rinne P, Hellberg S, Kiugel M, Virta J, Li XG, Käkelä M, et al. Comparison of somatostatin receptor 2-targeting PET tracers in the detection of mouse atherosclerotic plaques. Mol Imaging Biol. 2016;18(1):99-108. https://doi.org/10.1007/s11307-015-0873-1.

33. Tarkin JM, Joshi FR, Evans NR, Chowdhury MM, Figg NL, Shah $\mathrm{AV}$, et al. Detection of atherosclerotic inflammation by $68 \mathrm{Ga}-$ DOTATATE PET compared to [18F]FDG PET imaging. J Am
Coll Cardiol. 2017;69(14):1774-91. https://doi.org/10.1016/j.jacc. 2017.01.060.

34. Kabasakal L, Demirci E, Ocak M, Decristoforo C, Araman A, Ozsoy Y, et al. Comparison of (6)(8)Ga-DOTATATE and (6)(8)Ga-DOTANOC PET/CT imaging in the same patient group with neuroendocrine tumours. Eur J Nucl Med Mol Imaging. 2012;39(8):1271-7. https://doi.org/10.1007/s00259-012-2123-y.

35. Wester HJ, Keller U, Schottelius M, Beer A, Philipp-Abbrederis K, Hoffmann F, et al. Disclosing the CXCR4 expression in lymphoproliferative diseases by targeted molecular imaging. Theranostics. 2015;5(6):618-30. https://doi.org/10.7150/thno.11251.

36. Gourni E, Demmer O, Schottelius M, D’Alessandria C, Schulz S, Dijkgraaf I, et al. PET of CXCR4 expression by a (68)Ga-labeled highly specific targeted contrast agent. J Nucl Med. 2011;52(11): 1803-10. https://doi.org/10.2967/jnumed.111.098798.

37.• Thackeray JT, Derlin T, Haghikia A, Napp LC, Wang Y, Ross TL, et al. Molecular imaging of the chemokine receptor CXCR4 after acute myocardial infarction. JACC Cardiovasc Imaging. 2015;8(12):1417-26. This study shows, that PET imaging with 68Ga-pentixafor allows for identifying CXCR4 receptor upregulation in the infarcted region in patient after acut myocardial infarction. https://doi.org/10.1016/j.jcmg.2015.09.008.

38.• Weiberg D, Thackeray JT, Daum G et al. Clinical molecular imaging of chemokine receptor CXCR4 expression in atherosclerotic plaque using 68Ga-pentixafor PET: correlation with cardiovascular risk factors and calcified plaque burden. J Nucl Med. 2017. An essentail trial which shows that arterial wall 68Ga-Pentixafor uptake is significantly associated with surrogate hallmarks of atherosclerosis and is linked to the presence of cardiovascular risk factors.

39. Jabłoński A. Efficiency of anti-Stokes fluorescence in dyes. Nature. 1933;131(3319):839-40. https://doi.org/10.1038/131839b0.

40. Hong G, Antaris AL, Dai H. Near-infrared fluorophores for biomedical imaging. Nat Biomed Eng. 2017;1(1) https://doi.org/10. 1038/s41551-016-0010.

41. Sevick-Muraca EM, Rasmussen JC. Molecular imaging with optics: primer and case for near-infrared fluorescence techniques in personalized medicine. J Biomed Opt. 2008;13(4):041303. https:// doi.org/10.1117/1.2953185.

42. Mahmood U, Tung CH, Tang Y, Weissleder R. Feasibility of in vivo multichannel optical imaging of gene expression: experimental study in mice. Radiology. 2002;224(2):446-51. https://doi.org/10. 1148/radiol.2242011589.

43. Aikawa E, Nahrendorf M, Sosnovik D, Lok VM, Jaffer FA, Aikawa $\mathrm{M}$, et al. Multimodality molecular imaging identifies proteolytic and osteogenic activities in early aortic valve disease. Circulation. $2007 ; 115(3): 377-86$. https://doi.org/10.1161/ CIRCULATIONAHA.106.654913.

44. Jaffer FA, Kim DE, Quinti L, Tung CH, Aikawa E, Pande AN, et al. Optical visualization of cathepsin $\mathrm{K}$ activity in atherosclerosis with a novel, protease-activatable fluorescence sensor. Circulation. 2007;115(17):2292-8. https://doi.org/10.1161/ CIRCULATIONAHA.106.660340.

45. Ntziachristos V, Weissleder R. Experimental three-dimensional fluorescence reconstruction of diffuse media by use of a normalized Born approximation. Opt Lett. 2001;26(12):893-5. https://doi.org/ 10.1364/OL.26.000893.

46. Nahrendorf M, Waterman P, Thurber G, Groves K, Rajopadhye M, Panizzi P, et al. Hybrid in vivo FMT-CT imaging of protease activity in atherosclerosis with customized nanosensors. Arterioscler Thromb Vasc Biol. 2009;29(10):1444-51. https://doi.org/10.1161/ ATVBAHA.109.193086.

47. Li B, Maafi F, Berti R, Pouliot P, Rhéaume E, Tardif JC, et al. Hybrid FMT-MRI applied to in vivo atherosclerosis imaging. Biomed Opt Express. 2014;5(5):1664-76. https://doi.org/10.1364/ BOE.5.001664. 
48. Chen J, Tung CH, Mahmood U, Ntziachristos V, Gyurko R, Fishman MC, et al. In vivo imaging of proteolytic activity in atherosclerosis. Circulation. 2002;105(23):2766-71. https://doi.org/ 10.1161/01.CIR.0000017860.20619.23.

49. Deguchi JO, Aikawa M, Tung CH, Aikawa E, Kim DE, Ntziachristos $\mathrm{V}$, et al. Inflammation in atherosclerosis: visualizing matrix metalloproteinase action in macrophages in vivo. Circulation. 2006;114(1): 55-62. https://doi.org/10.1161/CIRCULATIONAHA.106.619056.

50. Lutgens E, Lutgens SP, Faber BC, Heeneman S, Gijbels MM, de Winther MP, et al. Disruption of the cathepsin K gene reduces atherosclerosis progression and induces plaque fibrosis but accelerates macrophage foam cell formation. Circulation. 2006;113(1):98107. https://doi.org/10.1161/CIRCULATIONAHA.105.561449.

51. Tan C, Liu Y, Li W, Deng F, Liu X, Wang X, et al. Associations of matrix metalloproteinase-9 and monocyte chemoattractant protein1 concentrations with carotid atherosclerosis, based on measurements of plaque and intima-media thickness. Atherosclerosis. 2014;232(1):199-203. https://doi.org/10.1016/j.atherosclerosis. 2013.11.040.

52. Newby AC. Metalloproteinase production from macrophages-a perfect storm leading to atherosclerotic plaque rupture and myocardial infarction. Exp Physiol. 2016;101(11):1327-37. https://doi. org/10.1113/EP085567.

53. Rodriguez-Menocal L, Wei Y, Pham SM, St-Pierre M, Li S, Webster K, et al. A novel mouse model of in-stent restenosis. Atherosclerosis. 2010;209(2):359-66. https://doi.org/10.1016/j. atherosclerosis.2009.09.071.

54.• Libby P, Pasterkamp G. Requiem for the 'vulnerable plaque'. Eur Heart J. 2015;36(43):2984-7. A relevant review, which describes the reshaped course of atherosclerosis due to current medical regime. https://doi.org/10.1093/eurheartj/ehv349.

55. Tricot O, Mallat Z, Heymes C, Belmin J, Leseche G, Tedgui A. Relation between endothelial cell apoptosis and blood flow direction in human atherosclerotic plaques. Circulation. 2000;101(21): 2450-3. https://doi.org/10.1161/01.CIR.101.21.2450.

56. Von Spiegel T, Scholz M, Wietasch G, et al. Perioperative monitoring of indocyanine green clearance and plasma disappearance rate in patients undergoing liver transplantation. Anaesthesist. 2002;51(5):359-66. https://doi.org/10.1007/s00101-002-0290-0.

57. Maarek JM, Holschneider DP, Rubinstein EH. Fluorescence dilution technique for measurement of cardiac output and circulating blood volume in healthy human subjects. Anesthesiology. 2007;106(3):491-8. https://doi.org/10.1097/00000542200703000-00013.

58. Pang CE, Shah VP, Sarraf D, Freund KB. Ultra-widefield imaging with autofluorescence and indocyanine green angiography in central serous chorioretinopathy. Am J Ophthalmol. 2014;158(2):36271 e2. https://doi.org/10.1016/j.ajo.2014.04.021.

59. Yoneya S, Saito T, Komatsu Y, Koyama I, Takahashi K, DuvollYoung J. Binding properties of indocyanine green in human blood. Invest Ophthalmol Vis Sci. 1998;39(7):1286-90.

60. Werner SG, Langer HE, Schott P, Bahner M, Schwenke C, LindAlbrecht $\mathrm{G}$, et al. Indocyanine green-enhanced fluorescence optical imaging in patients with early and very early arthritis: a comparative study with magnetic resonance imaging. Arthritis Rheum. 2013;65(12):3036-44. https://doi.org/10.1002/art.38175.

61. Vinegoni C, Botnaru I, Aikawa E, Calfon MA, Iwamoto Y, Folco $\mathrm{EJ}$, et al. Indocyanine green enables near-infrared fluorescence imaging of lipid-rich, inflamed atherosclerotic plaques. Sci Trans1 Med. 2011;3(84):84ra45. https://doi.org/10.1126/scitranslmed. 3001577.

62. Verjans JW, Osborn EA, Ughi GJ, Calfon Press MA, Hamidi E, Antoniadis AP, et al. Targeted near-infrared fluorescence imaging of atherosclerosis: clinical and intracoronary evaluation of indocyanine green. JACC Cardiovasc Imaging. 2016;9(9):1087-95. The first-in-human study of indocyanine green, which targets carotid plaques exhibiting decreased endothelial integrity. https://doi.org/10.1016/j.jcmg.2016.01.034.

63. Jaffer FA, Vinegoni C, John MC, Aikawa E, Gold HK, Finn AV, et al. Real-time catheter molecular sensing of inflammation in proteolytically active atherosclerosis. Circulation. 2008;118(18):18029. https://doi.org/10.1161/CIRCULATIONAHA.108.785881.

64. Jaffer FA, Calfon MA, Rosenthal A, Mallas G, Razansky RN, Mauskapf A, et al. Two-dimensional intravascular near-infrared fluorescence molecular imaging of inflammation in atherosclerosis and stent-induced vascular injury. J Am Coll Cardiol. 2011;57(25):251626. https://doi.org/10.1016/j.jacc.2011.02.036.

65. Nakazawa G, Finn AV, Joner M, Ladich E, Kutys R, Mont EK, et al. Delayed arterial healing and increased late stent thrombosis at culprit sites after drug-eluting stent placement for acute myocardial infarction patients: an autopsy study. Circulation. 2008;118(11):1138-45. https://doi.org/10.1161/CIRCULATIONAHA.107.762047.

66. Joner M, Finn AV, Farb A, Mont EK, Kolodgie FD, Ladich E, et al. Pathology of drug-eluting stents in humans: delayed healing and late thrombotic risk. J Am Coll Cardiol. 2006;48(1):193-202. https://doi.org/10.1016/j.jacc.2006.03.042.

67. Bonaa KH, Mannsverk J, Wiseth R, et al. Drug-eluting or baremetal stents for coronary artery disease. N Engl J Med. 2016;375(13):1242-52. https://doi.org/10.1056/NEJMoa1607991.

68. Tearney GJ, Waxman S, Shishkov M, Vakoc BJ, Suter MJ, Freilich MI, et al. Three-dimensional coronary artery microscopy by intracoronary optical frequency domain imaging. JACC Cardiovasc Imaging. 2008;1(6):752-61. https://doi.org/10.1016/j.jcmg.2008.06.007.

69. Yoo H, Kim JW, Shishkov M, Namati E, Morse T, Shubochkin R, et al. Intra-arterial catheter for simultaneous microstructural and molecular imaging in vivo. Nat Med. 2011;17(12):1680-4. https://doi.org/10.1038/nm.2555.

70. Ughi GJ, Verjans J, Fard AM, Wang H, Osborn E, Hara T, et al. Dual modality intravascular optical coherence tomography (OCT) and near-infrared fluorescence (NIRF) imaging: a fully automated algorithm for the distance-calibration of NIRF signal intensity for quantitative molecular imaging. Int $\mathrm{J}$ Cardiovasc Imaging. 2015;31(2):259-68. https://doi.org/10.1007/s10554-014-0556-z.

71. Lee S, Lee MW, Cho HS, Song JW, Nam HS, Oh DJ, et al. Fully integrated high-speed intravascular optical coherence tomography/ near-infrared fluorescence structural/molecular imaging in vivo using a clinically available near-infrared fluorescence-emitting indocyanine green to detect inflamed lipid-rich atheromata in coronary-sized vessels. Circ Cardiovasc Interv. 2014;7(4):560-9. This study shows, that an integrated OCT-NIRF catheter using indocyanine green is able to accurately identify lipid-rich plaqes in coronary-sized vessels in rabbits. https://doi.org/10.1161/ CIRCINTERVENTIONS.114.001498.

72. Kim S, Lee MW, Kim TS, Song JW, Nam HS, Cho HS, et al. Intracoronary dual-modal optical coherence tomography-near-infrared fluorescence structural-molecular imaging with a clinical dose of indocyanine green for the assessment of high-risk plaques and stentassociated inflammation in a beating coronary artery. Eur Heart J. 2016;37(37):2833-44. https://doi.org/10.1093/eurheartj/ehv726.

73. Wang H, Gardecki JA, Ughi GJ, Jacques PV, Hamidi E, Tearney GJ. Ex vivo catheter-based imaging of coronary atherosclerosis using multimodality OCT and NIRAF excited at $633 \mathrm{~nm}$. Biomed Opt Express. 2015;6(4):1363-75. https://doi.org/10.1364/BOE.6.001363.

74. Ughi GJ, Wang H, Gerbaud E, Gardecki JA, Fard AM, Hamidi E, et al. Clinical characterization of coronary atherosclerosis with dual-modality OCT and near-infrared autofluorescence imaging. JACC Cardiovasc Imaging. 2016;9(11):1304-14. This study demonstrates the feasibilty of the dual-modality OCT/NIRAF (near-infrared autofluorescence) catheter to detect high-risk plaques in patients with coronary artery disease. https://doi. org/10.1016/j.jcmg.2015.11.020. 